\title{
Building Cultural Competence and Changing Cultural Perceptions: Students from the UAE and USA Participate in a Cultural Exchange Project
}

\author{
Leslie Seawright ${ }^{1}$, Robyn Albers ${ }^{2}$, Susan Schanne ${ }^{3}$
}

\author{
${ }^{1}$ Missouri State University, Springfield, MO, USA \\ ${ }^{2}$ Zayed University, Dubai, UAE \\ ${ }^{3}$ Eastern Michigan University, Ypsilanti, MI, USA
}

Objectives: Cultural competence is a skill that is lauded and encouraged in today's business communication programs and in industry. The problem becomes, how and when do instructors introduce students to meaningful intercultural exchanges that produce the skills and awareness students will need in the future. The instructors in this study wanted a low-cost, student-center program or assignment to introduce students to intercultural communication through actual practice. The project needed to help students become more culturally aware and culturally competent.

Methods: The authors of this study paired their students for a virtual cross-cultural exchange for a period of 8 weeks. Students from the United States of America (USA) and the United Arab Emirates (UAE) spent several weeks corresponding via the text messaging application, WhatsApp, in order to learn more about the other's culture and customs. Surveys intended to measure cultural awareness and cultural competence were taken by students prior to the start of the exchange and again at its conclusion.

Results: The survey results show an increase in cultural awareness and cultural competence correlated to the cultural exchange project.

Conclusions: Instructors can create low-cost, interactive opportunities for students to improve cultural awareness and competence through online conversations and cultural exchanges with students of various cultures in different locales and countries.

Key Words: Cultural Competence, Cultural Perception, Intercultural Communication, Cultural Awareness, Globalization

\section{Introduction}

There is little doubt that if students want to succeed and become

Received: Jul 23, 2020 Revised: Oct 5, 2020 Accepted: Nov 23, 2020 Corresponding author: Robyn Albers

PO Box 144534, Zayed University, Abu Dhabi, UAE

Tel: +971507211413, E-mail: Robyn.Albers@zu.ac.ae

This is an Open Access article distributed under the terms of the Creative Commons Attribution Non-Commercial License (http://creativecommons.org/licenses/ by-nc/4.0/) which permits unrestricted non-commercial use, distribution, and reproduction in any medium, provided the original work is properly cited.

Copyright $\odot 2021$ Korean Association for Business Communication. leaders in their fields, they must do so in a business environment that is increasingly more global in scale (Price, 2016; Shetty \& Rudell, 2002; Tuleja, 2008; Ulijn, O'Hair, Weggeman, Ledlow, \& Hall, 2000; Varner, 2000). Research on how to prepare students for the global business environment suggests everything from learning a foreign language (Vigier \& Smoller Le Floch, 2011) participating in study abroad programs (Heffron \& Maresco, 2014; Mikhaylov, 2014) holding international internships (Du-Babcock, 2016) to forming asynchronous online discussions (Hew, Cheung, \& Ng, 2010). While the methods are effective, time and money often restrict students' ability to study a foreign language or embark on an international study abroad 
or internship opportunity. The authors of this study suggest a low-cost possibility for increasing cultural awareness and cultural competence in students.

In 2019, Author 2 from Name Withheld University approached two professors based in the United States of America (USA), Author 1 from Name Withheld State University and Name Withheld from University of Name Withheld, to gage their interest in creating a cultural exchange project. The instructors agreed that an online cultural exchange, in which students from different countries could converse on a regular basis, would provide students authentic practice of intercultural communication skills and provide students an opportunity to balance the theory and practice of intercultural communication.

The eight-week project they created consisted of a virtual exchange, facilitated through the text messaging app WhatsApp, between Emirati and American students to promote cultural awareness and increase students' cultural competence.

Two research questions (RQs) guided the creation of the cultural exchange project and the data analysis that resulted from two student surveys.

RQ1: Do student cultural perceptions change when communication between different cultures, enhanced with the use of social media tools, is encouraged and facilitated in business communication classes?

RQ2: Will an online cultural exchange project increase students' cultural competence?

\section{Literature Review}

\section{Defining Cultural Awareness and Cultural Competence}

The National Center for Cultural Competence defines cultural awareness as "being cognizant, observant, and conscious of similarities and differences among and between cultural groups" (Goode, 2006). Winkelman (2005) adds, "cultural self-awareness includes recognition of one's own cultural influences upon values, beliefs, and judgments, as well as the influences derived from the professional's work culture" (p. 9). Cultural awareness is a critical component of cultural competence. Without the awareness of one's own culture there is little ability to become competent in communicating with those of other cultures.

Johnson, Lenartowicz, and Apud (2006) created a definition of cultural competence specific to international business. They claim, "cross-cultural competence in international business is an individual's effectiveness in drawing upon a set of knowledge, skills, and personal attributes in order to work successfully with people from different national cultural backgrounds at home or abroad" (Johnson et al., 2006, p. 530). Their definition works well for the current study because the instructors worked to create new knowledge through specific instruction on cultural communication theory. In tandem, they provided opportunities for students to develop new skills by practicing intercultural communication with peers in another country.

Sue (2001) argues that being aware of personal attitudes towards others and understanding personal discomfort with difference is a key trait of developing cultural competence. The current study allowed students to become aware of their personal attitudes towards others and reflect on those attitudes throughout the project.

\section{Cultural Perceptions of Communication}

The cultural perception of individuals is a function of, and is tied to, the dominant culture. Khatib (2015) adds, "Cultural perception can be clouded by stereotypes, which are both descriptive and prescriptive" (p. 506). Understanding cultural perceptions of communication strengthens a person's understanding of their own culture while creating greater appreciation for other cultures.

A 2017 study conducted by Morrison and Schanne of more than 1,600 companies in 31 industries found that two of the most important "soft skills" needed by new graduates included the ability to interpret the meaning of a message and the ability to listen for and interpret meaning. Basic communication skills of understanding and interpreting the meaning of a message become more complex when the message is created using a different cultural frame.

In order to build cultural competence, students must start with cultural awareness, the knowledge and understanding of their own culture. Thrush (1993) suggests that improved awareness of culture on the part of the student, and a better understanding of potential problems in the intercultural communication process, is crucial to a student's learning (p. 280). Becoming aware of one's own culture allows a student the opportunity to compare and contrast communication from the knowledge of their own cultural distinctions.

While most cultures have elements of high- and low-context characteristics, the USA is recognized as a low-context culture (Hall, 1976). Characteristics of communicators in the USA can dramatically contrast when working with those of other cultures, especially cultures found in the Arab world (Zaharna, 1995), which are typically considered high-context cultures (Hall, 1976). Even online, the American cultural preference is for direct communication based on precise information, facts, and expectations. However, Arab cultures prefer form over function. Zaharna (1995) claims, "whereas an American may insert facts and figures to illustrate a point, and Arab speaker may use one strong, vivid example to convey a point. An Arab 
speaker also tends to be very generous in her use of descriptive adjectives and adverbs" (para. 26). As Luck and Swartz (2018) found, a single word misunderstood or used differently between two cultures can change the nature and understanding of communication. Thus, cultural perceptions of communication are critical to understanding language and how it works in various cultures. As Uzun (2014) notes, students must be aware of communication distinctions between cultures, such as high-context and low-context in order to "feel willing to endure any potential misunderstanding or disagreement" (p. 2409).

\section{Experiencing Intercultural Communication}

A study conducted by the Interfaith Youth Core found that students who experienced intercultural and interpersonal relationships with those of different faiths became more empathetic and understanding (Johnson, 2019). Significantly, "the study showed that students who gain a friend with a particular worldview view more positively not only members of that demographic, but people with other worldviews as well. These effects seem to generalize through people's social networks" (Johnson, 2019, para. 8). Additionally, when students maintained those intercultural friendships, they were able to work through conflict and maintain friendships with those they disagreed with politically (Johnson, 2019, para. 9).

St. Amant (2006) suggests that exercises in which students interact in real time with counterparts from other cultures help students better appreciate how cultural factors affect exchanges. Interaction via virtual means aids in the humanization of participants, allowing students to work with individuals instead of unknown, faceless, and nameless entities on the other side of an Internet connection.

Exercises and projects designed to expose students to different cultures and encourage intercultural communication can aid students in developing better communication and other business skills. Randazzo-Davis and Nelson (2020) found that students with better intercultural intelligence and global knowledge are equated with better outcomes for their virtual teams.

\section{Methodology}

The current study consisted of 177 students in the United Arab Emirates (UAE) and USA communicating on WhatsApp about various aspects of their cultures. These conversations took place for 8 weeks. Quantitative data from pre- and post-exchange surveys were collected along with qualitative open-ended responses to questions on the same surveys.

\section{Participants}

A total of 177 students participated in the cultural exchange project. Of those, 144 were at Zayed University in the UAE. Author 2 designed an assignment tied to the project, so students were motivated to participate. Students from the UAE were all native Emiratis, fluent in Arabic with good to excellent proficiency in English. Author 1 sought out volunteers among her current and past technical writing students. Ultimately 22 students at Name Withheld State University volunteered to participate in the project. The students from Name Withheld State University were all traditional students from the USA and L1 English speakers. The remaining 11 students were enrolled in Name Withheld's business communication course at the University of Name Withheld. Assignments related to the project encouraged students to participate. These 11 students were traditional students from the USA and L1 English speakers. All 177 student participants were divided into female and male groups in consideration of cultural restrictions in the UAE, where it is common in educational institutions to segregate students by gender.

Before the virtual exchange project began, students received instruction on intercultural communication, including information on differences between high and low-context cultures (Hall, 1976), individualism and collectivism, and other cultural dimensions as defined by Hofstede (2019).

\section{Cultural Exchange Project Overview}

Emirati students first formed groups of 4-6 students. These group members were then matched with one American student from either Missouri or Maine. In some instances, a second American student was added to the group. The Emirati students initiated communication by writing a group email introducing themselves using email addresses provided by the authors.

The group members then began communicating frequently and informally via WhatsApp ${ }^{1}$ using the group chat/text function. Each week, Emirati students were given a theme and several questions to discuss with their USA counterparts. The USA students would then respond by answering the same questions and remarking on interesting similarities and differences. Students were instructed to share their culture via photos, videos, and text to learn about Emirati/American culture.

Students shared with their group members on various topics each week for eight weeks. Topics for discussion included family, sports, summer vacation, concepts of beauty and style, animals and pets, university life, food, travel, social media, leisure

\footnotetext{
${ }^{1}$ In the UAE, Skype is not accessible; WhatsApp is the most widely used communication app because it is free and enables the user(s) to create group chats and to send photos and videos.
} 
time, and health.

For example, in Week One, students were asked to share on the topic of marriage and relationships. Questions to consider and answer included: At what age do most of your friends/family get married; How do you propose; How do people typically meet their future wife/husband; Describe a typical wedding in detail and share photos and costs if possible; Can you have more than one wife/husband; How do you get a house after you are married; Where do you usually live after marriage; What is the biggest stress on marriages in your country?

\section{Survey}

Student participants in the UAE and USA were asked to complete a survey through Google Forms before the start of the cultural exchange project and to complete the same survey at the end of the project.

The survey was divided into three parts. Part One consisted of 8 survey questions/statements adapted from the "Cultural Competence Self-Assessment Checklist" used by several different diversity initiatives and organizations (Central Vancouver Island Multicultural Society, 2015). Eight statements were selected from the Cultural Competence Self-Assessment Checklist for use in the study survey. These statements were selected for the project because they were the most general statements from the competence checklist and provided a starting point for students and researchers to consider cultural competence. In addition, the scale was changed from a 4-point scale of "never" to "always" to a 5-point Likert scale of "strongly disagree" to "strongly agree." The change in scale was necessary because many of the USA students had few intercultural experiences to draw from. It was easier for them to agree or disagree with a statement rather than deciding if they "never" or "always" behaved in a specific way in an intercultural encounter.

Part Two of the survey, statements 9-14, asked American students to reveal their views of Arab people. These statements were developed by the instructors of the project to gauge cultural perceptions and stereotypes of Arabs specific to American students. Part Three of the survey, statements 15-20, repeated the statements in 9-14 but were specific to how Arab students viewed Americans.

Students were encouraged, but not required, to respond to the pre- and post-exchange surveys. The response rate was excellent at $92 \%$. The responses to the Likert-scale statements were evaluated through mean scores and standard deviation calculations. In addition, the change of mean scores from preto post-exchange surveys was recorded for each statement. Qualitative responses to open-ended questions on the survey were coded by the authors based on the number of times a similar statement or theme was evident in student responses. Themes emerging from American student responses included: "I don't know any Arab people" and "they (Arabs) are different than us." Themes emerging from Arab student responses included: "they (Americans) are kind" and "they (Americans) don't seem to know much about our culture." A common theme of both cultures was "we don't have very much in common."

\section{Results}

Student responses to the quantitative survey statements are identified in Tables 1-3. The qualitative statements made in response to open-ended questions on the survey are discussed in the findings that follow.

\section{Research Question 1}

A review of survey responses to statements 9-20 and open-ended responses to survey questions reveal our findings for RQ1.

In statements 9 and 15, students were asked if they were comfortable communicating with those of the opposite culture. Students could select $1-5$ on a Likert scale, where 1 represented "strongly disagree" and 5 represented "strongly agree." In pre-exchange surveys, American scores averaged 4.47 to this statement. The post-exchange response increased 0.22 to 4.69 . As this response was given at the conclusion of the project, it is assumed that all students who responded to this question were reporting on actual and recent interactions with their peers in the UAE. The increase in comfort of Americans versus Arabs is interesting, as the Arab score on this statement only increased by 0.07 . This smaller increase may be explained because of the UAE's large population of expatriates. The United Nations (2017) estimates the total population in the UAE is made up of only 12\% Emirati. Therefore, many UAE students have experience speaking with and interacting with Americans and other nationalities, though rarely with people their own age. USA students, and particularly those participating in this project, rarely have the opportunity to practice communication with Arabs in the USA.

Survey statement 11 asked American students to agree or disagree that they had a lot in common with Arabs. Similarly, survey statement 17 asked Arab students to agree or disagree that they had a lot in common with Americans. These questions had different initial responses between the two cultures. American students felt there was a good amount of commonality between themselves and their Arab counterparts, as their responses averaged 3.9. Conversely, Arab students averaged 3.08 in pre-exchange surveys.

These results are supported by the open-ended responses 
Table 1. Survey section one: All students

\begin{tabular}{|c|c|c|c|c|c|}
\hline Survey statement & $\begin{array}{l}\text { Pre-survey } \\
(n=163)\end{array}$ & $S D$ & $\begin{array}{l}\text { Post-survey } \\
\qquad(n=163)\end{array}$ & $S D$ & Change \\
\hline 1. I view human difference as positive and a cause for celebration. & 4.12 & 0.97 & 4.30 & 0.86 & +0.18 \\
\hline $\begin{array}{l}\text { 2. I take any opportunity to put myself in places where I can learn } \\
\text { about differences and create relationships. }\end{array}$ & 4.04 & 0.96 & 4.25 & 0.88 & +0.21 \\
\hline 3. I have a clear sense of my own ethnic, cultural, and racial identity. & 4.38 & 0.90 & 4.44 & 0.81 & +0.06 \\
\hline $\begin{array}{l}\text { 4. I am aware that in order to learn more about others I need to } \\
\text { understand and be prepared to share my own culture. }\end{array}$ & 4.46 & 0.84 & 4.50 & 0.83 & +0.04 \\
\hline $\begin{array}{l}\text { 5. I am aware of my discomfort when I encounter differences in race, } \\
\text { religion, sexual orientation, language, and disability/physical } \\
\text { challenges. }\end{array}$ & 3.53 & 1.18 & 3.82 & 1.08 & +0.29 \\
\hline $\begin{array}{l}\text { 6. I am aware of the assumptions that I hold about people of different } \\
\text { cultures. }\end{array}$ & 3.66 & 1.00 & 3.93 & 0.99 & +0.27 \\
\hline $\begin{array}{l}\text { 7. I am aware of my stereotypes as they arise and have developed } \\
\text { strategies for reducing the harm they cause. }\end{array}$ & 3.86 & 1.01 & 4.00 & 1.01 & +0.14 \\
\hline $\begin{array}{l}\text { 8. I am aware of how my cultural perspective influences my } \\
\text { judgement about what are "appropriate","normal", or "superior" } \\
\text { behaviors, values, and communication styles. }\end{array}$ & 4.03 & 0.97 & 4.10 & 0.93 & +0.07 \\
\hline
\end{tabular}

Note. SD, standard deviation.

Table 2. Survey section two: American students only

\begin{tabular}{|c|c|c|c|c|c|}
\hline Survey statement & $\begin{array}{c}\text { Pre-survey } \\
(n=30)\end{array}$ & $S D$ & $\begin{array}{c}\text { Post-survey } \\
\quad(n=16)\end{array}$ & $S D$ & Change \\
\hline 9. I am comfortable communicating with Arab people. & 4.47 & 0.73 & 4.69 & 0.60 & +0.22 \\
\hline 10. I believe that Arabs are kind. & 4.43 & 0.82 & 4.75 & 0.77 & +0.32 \\
\hline 11. I believe that I have a lot in common with Arab people. & 3.90 & 0.99 & 4.31 & 0.95 & +0.41 \\
\hline 12. I believe Arabs are dangerous. & 1.50 & 0.78 & 1.19 & 0.40 & -0.31 \\
\hline 13. I feel I can trust Arabs. & 4.17 & 1.02 & 4.38 & 1.09 & +0.21 \\
\hline 14. In general, I like Arabs. & 4.33 & 0.76 & 4.63 & 0.81 & +0.30 \\
\hline
\end{tabular}

Note. SD, standard deviation.

Table 3. Survey section three: Arab students only

\begin{tabular}{|c|c|c|c|c|c|}
\hline Survey statement & $\begin{array}{r}\text { Pre-survey } \\
(n=132)\end{array}$ & $S D$ & $\begin{array}{r}\text { Post-survey } \\
(n=147)\end{array}$ & $S D$ & Change \\
\hline 15. I am comfortable communicating with American people. & 4.31 & 0.83 & 4.38 & 0.95 & +0.07 \\
\hline 16. I believe that Americans are kind. & 4.02 & 0.89 & 4.22 & 0.95 & +0.20 \\
\hline 17. I believe that I have a lot in common with American people. & 3.08 & 1.07 & 3.61 & 1.09 & +0.53 \\
\hline 18. I believe American are dangerous. & 1.75 & 0.98 & 1.93 & 1.24 & +0.18 \\
\hline 19. I feel I can trust Americans. & 3.37 & 0.90 & 3.69 & 0.93 & +0.32 \\
\hline 20. In general, I like Americans. & 3.95 & 0.95 & 4.18 & 0.89 & +0.23 \\
\hline
\end{tabular}

Note. SD, standard deviation.

from Arab students who felt they did not have a lot in common due to differences in their culture, beliefs, and religion. One Arab student commented, "I don't think that we have things in common considering the culture and the religion." Similarly, another Arab student noted, "I think there is a huge contrast be- tween my culture and the American culture. I currently have no perceptions about Americans." Several American students also described differences in the cultures. Pre-exchange responses included, "I believe that Arabic people lead a very different life and culture compared to the ideals and culture found in West- 
ern society," and "They may have different cultural backgrounds than I do. They typically eat with their hands, segregate their sexes, dress in traditional garb (dishdasha), and if they're from the Arab nations are most likely practice the Muslim faith."

The post-exchange survey responses to statements 11 and 17 indicate that the students experienced a significant change in their cultural perceptions after communicating with each other for eight weeks. The Arab students' average score increased 0.53 raising the overall rating to 3.61 , while the American students' average score increased 0.41 raising the overall rating to 4.31 . These changes were the most dramatic of all the pre- to post-exchange increases. One American student wrote at the end of the project, "After communicating with my group throughout the semester, I didn't realize that I would find so much in common with them. Before, I had the perception that we were very different." Similarly, one Arab student wrote, "Americans are not so different from us. We could get along pretty well if we keep an open mind have a mutual respect for one another."

Getting to know a person and their background is very important for trust in a high-context country such as the UAE. Survey statements 13 and 19 gauged trust for Arabs by Americans and vice versa. The survey response means increased from pre- to post-exchange by 0.32 to 3.69 for Arab students and by 0.21 to 4.38 for American students. The majority of post-exchange responses to the open-ended survey questions from Arab students described the Americans as "kind, lovely, nice, and good". One Arab student noted, "I can trust them and do business with them."

Finally, students were asked to respond to the statements 14 and 20 about liking the other culture in general. In pre-exchange surveys, Americans agreed that in general they liked Arabs based on an average score of 4.33, despite admitting that they knew very few, if any, Arab people. Still, this project clearly made a positive impact on American students. Evidence from the post-survey showed positive change. American students averaged 4.63, an increase of 0.30 after the cultural exchange project. The open-ended questions supported the survey results with many students commenting on the unexpected similarities between the students. The students viewed the cultural traditions as different but felt they were similar at their core. Likewise, the Arab students had a positive movement from the pre-exchange to post-exchange survey results. The overall percentage of students agreeing they liked Americans in general increased 0.23 from 3.95 in pre-exchange surveys to 4.18 in post-exchange surveys. One student wrote, "I honestly never knew that I had so much similarities between my American counterpart and I. We shared many memories, experiences, and interests." Another Arab student wrote, "After finishing [the cultural exchange project], many perspectives I had about Americans have changed. I liked American people and it was interesting to know about their culture and many other things."

Overall, American-only statements 9-14 and Arab-only statements $15-20$ all show a positive change in cultural perceptions from pre- to post-exchange surveys, with the exception of statement 18 (I believe Americans are dangerous.). Responses to statement 18 resulted in a slight increase in agreement from 1.75 pre-exchange to 1.93 post-exchange. The standard deviation, however, for the post-exchange survey response is 1.24 , so the small positive change in agreement of 0.18 may not represent a true increase in this sentiment.

\section{Research Question 2}

Pre- and post-exchange survey responses to statements 1-8 directly address whether or not students gained awareness of their own and other cultures, especially student awareness of their own perceptions, discomfort, and assumptions. The statements for Part One of the survey were taken directly from the "Cultural Competence Self-Assessment Checklist."

Statement 5 asked students to consider their own awareness of discomfort when encountering differences in race, religion, sexual orientation, language, and disability. The average increase in ratings on this statement was the largest for Part One of the survey. The student average grew 0.29 points from 3.53 in pre-exchange surveys to 3.82 in post-exchange surveys. As students were getting to know each other and learning more about another culture, they became aware of how they felt meeting people who were from different races, religions, and backgrounds. One UAE student wrote, "We are similar in many things even if our cultures are different and the respects and love I got from them is more than enough." These results suggest that participation in the intercultural exchange project helped students improve their awareness of assumptions they may hold about people of different cultures.

Similarly, when students were asked if they were aware of the assumptions they hold about people of different cultures, the average increased from pre- to post-exchange surveys. Students averaged 3.66 in pre-exchange surveys but increased in agreement 0.27 points to 3.93 in post-exchange surveys. Several students noted in open-ended question responses that their initial thoughts about Arabs and Americans changed as a result of this project. One UAE student noted, "What I see and hear about them I thought that they are so rude, but when I get to know them closer they seem very kind and helpful." An American student wrote, "After communicating with my group throughout the semester, I didn't realize that I would find so much in common with them. Before, I had the perception that we were 
very different." Likewise, another American claimed, "Going into the exchange, I did not believe that I had much in common with the students in the UAE. After the exchange, I realize that, while there are some significant differences, we lead very similar lives."

Finally, when students were asked to respond to Statement 5, "I am aware of my stereotypes as they arise and have developed strategies for reducing the harm they cause," results demonstrate an increase of cultural competence related to stereotype awareness. Students agreeing with this statement rose 0.14 points from 3.86 in pre-exchange surveys to 4.00 in post-exchange surveys. Open-ended responses further demonstrated this point. One American student in the post-exchange survey noted, "I feel that the media wants Americans to see them [Arabs] as violent people, so we do, when in reality they are kind." Similarly, an Arab student wrote, "I had a wrong perspective about American people but after taking this business communication project and we communicate with American student I understand the barrier between us and them is knowing each other culture." The increase in the mean on this statement and the subsequent comments suggest that the project helped students become more aware of their stereotypes over the course of the project, an important element in becoming a more culturally competent person.

\section{Discussion}

This study sought to balance theory and application to allow students to move past cultural ethnocentrism and learn techniques to aid in intercultural communication. This online cultural exchange project was designed to impact the lives of both American and Emirati students who have either not had the opportunity to travel or who have not had the opportunity to have a meaningful and lengthy cultural exchange. The eightweek exchange provided participants with direct exposure to how people of other cultures think and interact and also gave participants a frame of reference for the intercultural theory learned in the classroom.

The results of this study demonstrate that students experienced modest increases in cultural awareness and cultural competence. The opportunity to learn more about another culture from those in the culture created an open and inviting space in which students could ask questions and discard stereotypes. The WhatsApp platform was successful in encouraging conversation, echoing the findings of Commander, Zhao, Gallagher, and You (2016) who found that online platforms enabled students from different countries to connect in an easy and economical way (Commander et al., 2016). The ability to ask questions freely allowed the students in this study to apply what they learned from the textbooks to their real discussions with virtual exchange students. These findings are similar to studies by Barnett-Queen, Blair, and Merrick (2005), Chang, Chen, and Hsu (2011), and Jorczak and Dupuis (2014) who all found that online discussions allowed for better knowledge construction, cross cultural understanding, and critical thinking.

This virtual cultural exchange allowed students to create a third culture where they could meet together and share information about their customs and their day-to-day lives. This study reflects the findings of McEwan and Sobre-Denton (2001) who claim that through virtual third cultures, people of various cultural backgrounds can apply cultural and social information to build online communities that promote intercultural relationships. In the third culture created through WhatsApp chat groups, students met their counterparts and discovered cultural similarities and dissimilarities.

The exchange also allowed students to move away from stereotypes and change their cultural perceptions. For example, several of the American students were surprised to learn that Netflix, Hip/Hop, rap and other popular music existed in the UAE. They were also interested to learn that many American fast-food chains were in the UAE and that Emirati students often indulged in fast food. Thus, the stereotype of young Arab people somehow isolated from modern music, food, and entertainment was dispelled.

Unlike cross-cultural exchanges that require students to work in teams and produce a document, analysis, or review (Du-Babcock \& Varner, 2008; Seawright, 2014; Starke-Meyerring \& Andrews, 2006), this study asked only for students to get to know one another. This project allowed students to devote their time to learning about the lives of their group members rather than concentrating on producing a school assignment. The authors of this study argue that students need more time getting to know one another before entering into an international/intercultural team project.

By structuring conversation and suggesting topics each week for the groups, the instructors were able to avoid the challenges of other recent studies. Deng, Chen, and Li (2017) noted that they, "encouraged the students to have casual and free talk on any topic that interested them. Nevertheless, they felt at a loss as to what they should talk about or discuss" (p. 14). Our study sought to improve students' cultural competence through meaningful conversation instead of through a complicated team project with various deliverables. In the future, the authors hope to combine both meaningful conversation and a team project in order to gain the most benefit of a cross cultural experience. 


\section{Limitation}

This study was limited by the number of American students who participated. While the UAE had 144 student participants, there were only 33 American students. In future exchange projects, the authors would like a more equal number of students, so that the student groups could include $2-3$ students from each country. While USA students were able to meet 4 to 5 Emirati students, the Emiratis were only able to meet 1 or 2 American students.

In addition, the study was limited to 8 weeks. The authors agree that results could be improved by improving the ratio between Emirati and American students as well as lengthening the experience for students.

\section{Conclusion}

Results from this project demonstrate that cultural perceptions change when faculty can facilitate purposeful communication between students of different cultures. Cross cultural exchange projects can be low-cost and low-key endeavors. Cultural exchange projects like the one described in this paper can increase cultural competence and prepare students for the realities of globalization.

\section{References}

Barnett-Queen, T., Blair, R., \& Merrick, M. (2005). Student perspectives of online discussions: Strengths and weaknesses. Journal of Technology in Human Services, 23(3-4), 229-244.

Central Vancouver Island Multicultural Society. (2015). Cultural competence self-assessment checklist. Retrieved from http:// www.coloradoedinitiative.org/wp-content/uploads/2015/10/cultural-competence-self-assessment-checklist.pdf

Chang, C. K., Chen, G. D., \& Hsu, C. K. (2011). Providing adequate interactions in online discussion forums using few teaching assistants. The Turkish Online Journal of Educational Technology, 10(3), 193-202.

Commander, N., Zhao, Y., Gallagher, P., \& You, Y. (2016). Cross-national online discussions: International learning experiences with American and Chinese students in higher education. Innovations in Education and Teaching International, 53(4), 365-374.

Deng, L., Chen, Y. H., \& Li, S. C. (2017). Supporting cross-cultural online discussion with formal and informal platforms: A case between Hong Kong and Taiwan. Research and Practice in Technology Enhanced Learning, 12(1), 1-15.

Du-Babcock, B. (2016). Bridging the gap from classroom-based learning to experiential professional learning: A Hong Kong case. Dinamika Ilmu, 16(2), 181-199.
Du-Babcock, B., \& Varner, I. (2008). Intercultural business communication in action: Analysis of an international videoconference. In D. Starke-Meyerring, \& M. Wilson (Eds.), Designing globally networked learning environments: Visionary partnerships, policies, and pedagogies (pp. 156-169). Rotterdam, Netherlands: Sense.

Goode, T. (2006). Key definitions. Washington, DC: National Center for Cultural Competence, Georgetown University Center for Child and Human Development.

Hall, E. (1976). Beyond culture. Garden City, NY: Anchor Press.

Heffron, S., \& Maresco, P. A. (2014). The value of international experiences for business students: Measuring business student attitudes toward study abroad. Journal of International Students, 4(4), 351-362.

Hew, K. F., Cheung, W. S., \& Ng, C. S. L. (2010). Student contribution in asynchronous online discussion: A review of the research and empirical exploration. Instructional Science, 38(6), 571-606.

Hofstede, G. (2019). Compare countries. Hofstede Insights. Retrieved from http://www.hofstede-insights.com/product/ compare-countries/

Johnson, E., (2019, October 15). Varied friendships make students more tolerant. Inside Higher Ed. Retrieved from https://www. insidehighered.com/news/2019/10/15/college-students-friendsdifferent-worldviews-are-more-tolerant-study-finds

Johnson, J. P., Lenartowicz, T., \& Apud, S. (2006). Cross-cultural competence in international business: Toward a definition and a model. Journal of International Business Studies, 37(4), 525-543.

Jorczak, R. L., \& Dupuis, D. N. (2014). Differences in classroom versus online exam performance due to asynchronous discussion. Journal of Asynchronous Learning Networks, 18(2), 1-9.

Khatib, H. (2015). Impact of perceptual biases on cultural perception towards the 'other': The case of Egypt versus the European Union. Contemporary Arab Affairs, 8(4), 505-522.

Luck, S. L., \& Swartz, S. (2018). What's in a word? Findings from experiential group intercultural communication projects. Business Communication Research and Practice, 1(2), 90-94.

McEwan, B., \& Sobre-Denton, M. (2011). Virtual cosmopolitanism: Constructing third cultures and transmitting social and cultural capital through social media. Journal of International and Intercultural Communication, 4(4), 252-258.

Mikhaylov, N. S. (2014). International business students' cross-cultural competence development: The Influence of the educational environment. Sage Open, 4(4). doi: 10.1177/2158244014564352

Morrison, R., \& Schanne, S. (2017, October 18-20). Teaching towards the workplace. Paper presented at the Association of Business Communication Annual Conference, Dun Laoghaire, Ireland.

Price, T. (2016). Adjusting classroom pedagogies for a globalizing technical communication field. Intercom, 464, 23-24. 
Randazzo-Davis, M., \& Nelson, C. (2020). International business education using global virtual teams: Relationship between cultural intelligence, global knowledge, and team performance. International Journal for Business Education, 160, 42-61.

Seawright, L. E. (2014). Teaching technical writing: Opportunities for international collaboration. International Journal of Engineering Pedagogy, 4(2), 28-30.

Shetty, A., \& Rudell, F. (2002). Internationalizing the business program: A perspective of a small school. Journal of Education for Business, 78(2), 103-110.

St. Amant, K. (2006). Globalizing rhetoric: Using rhetorical concepts to identify and analyze cultural expectations related to genres. Journal of Language and Communication Studies, 37, 47-66.

Starke-Meyerring, D., \& Andrews, D. (2006). Building a shared virtual learning culture: An international classroom partnership. Business Communication Quarterly, 69(1), 25-49.

Sue, D. W. (2001). Multidimensional facets of cultural competence. The Counseling Psychologist, 29(6), 790-821.

Thrush, E. A. (1993). Bridging the gaps: Technical communication in an international and multicultural society. Technical Communication Quarterly, 2(3), 271-283.

Tuleja, E. A. (2008). Aspects of intercultural awareness through an MBA study abroad program: Going 'backstage.' Business Com- munication Quarterly, 71(3), 314-337.

Ulijn, J., O’Hair, D., Weggeman, M., Ledlow, G., \& Hall, H. T. (2000). Innovation, corporate strategy, and cultural context: What is the mission for international business communication? Journal of Business Communication, 37(3), 293-316.

United Nations. (2017). World population prospects: The 2017 revision. Volume 1: Comprehensive tables (Report No. ST/ESA/SER. A/399). New York, NY: United Nations Department of Economic and Social Affairs, Population Division.

Uzun, L. (2014). Utilising technology for intercultural communication in virtual environments and the role of English. Procedia, Social and Behavioral Sciences, 116, 2407-2411.

Varner, I. I. (2000). The theoretical foundation for intercultural business communication: A conceptual model, Journal of Business Communication, 37(1), 39-57.

Vigier, M., \& Smoller Le Floch, N. (2011). Promoting cultural awareness in an international business program through foreign language communication, Global Business Languages, 16(1), 6.

Winkelman, M. (2005). Cultural awareness, sensitivity \& competence. Peosta, IA: Eddie Bowers.

Zaharna, R. (1995). Understanding cultural preferences of Arab communication patterns. Public Relations Review, 21(3), 241-255. 